\title{
What proportion of patients with myocardial infarction are suitable for thrombolysis?
}

\author{
NEIL MURRAY, JOHN LYONS, CLIVE LAYTON, RAPHAEL BALCON \\ From the Department of Cardiology, London Chest Hospital, London
}

SUMMARY Four hundred and three patients were considered for entry into a trial of intravenous streptokinase in suspected myocardial infarction. Three hundred and sixty seven $(91 \%)$ were excluded. Two hundred and sixty $(65 \%)$ did not meet the inclusion criteria and 45 of the remain $\overrightarrow{+}$ ing $143(35 \%)$ patients had contraindications to thrombolysis. This left $98(24 \%)$ patients who were suitable for thrombolysis and 42 of them were over 70 years, the upper age limit. Thus. according to this trial protocol $56(14 \%)$ patients were eligible for recruitment; 36 (9\%) patient\$ were finally randomised. These data suggest that treatment with intravenous streptokinase ma be applicable to only a small proportion of patients with myocardial infarction.

Experimental work has shown that early reperfusion after coronary artery occlusion limits myocardial damage. ${ }^{1}$ For this reason there is much current interest in the use of thrombolysis in the management of acute myocardial infarction. Reperfusion of the infarct related coronary artery by a direct intracoronary infusion of agents such as streptokinase occurs in approximately $75 \%$ of patients. ${ }^{2-4}$ Some studies have shown improvement in left ventricular function ${ }^{5}$ and short term survival. ${ }^{6}$ The application of intracoronary thrombolysis is, however, limited because it requires facilities for emergency coronary angiography, which are not widely available, particularly outside normal working hours.

Intravenous administration of a thrombolytic agent is a more practical approach. Early studies of 24 hour infusion regimens produced inconsistent results $^{78}$ and this treatment was not generally accepted. More recent trials have shown that high dose infusions of shorter duration produce a rate of clot lysis of approximately $60 \%{ }^{3}$-a rate that is only slightly lower than that obtained with intracoronary administration. Indeed, some workers believe that ultimately clot lysis may occur as frequently with intravenous as with intracoronary administration. ${ }^{39}$

Requests for reprints to Dr Neil Murray, The Regional Cardiac Centre, Groby Road Hospital, Leicester LE3 9QE.

Accepted for publication 15 September 1986
Good responses in left ventricular function ${ }^{10}$ and short term survival ${ }^{11}$ have been achieved by both methods. Intravenous administration has, therefore been put forward as a technique that could be genero ally applied in clinical practice.

Certain problems may limit the use of thromê bolytic treatment. Firstly, patients must be selected with care if haemorrhage and hypersensitivity are to be avoided. Secondly, thrombolysis should probably be performed within six hours of the onset of symptoms ${ }^{1}$ if myocardial salvage is to be achievedu Even in well equipped centres treatment will bo delayed to allow for the coronary angiography that is. required before intracoronary thrombolysis can b8 performed. The inverse relation between the amount of myocardial salvage and the time betwee? coronary occlusion and clot lysis makes the intra $>$ venous route more attractive. Prehospital delay may, however, be as important as in hospital oneș and they apply equally to intravenous and intracoronary administration. Thus it may be thas although intravenous thrombolysis has been widely advocated, it may not be as applicable as was at firs thought.

We are currently engaged in a multicentre trial tô investigate the role of high dose intravenous strep? tokinase in suspected myocardial infarction. Wळ report the reasons for the exclusion of patients frong the trial. This should indicate the proportion of patients with suspected myocardial infarction wh8 will be suitable for thrombolysis. 


\section{Patients and methods}

All patients presenting with a clinical diagnosis of suspected myocardial infarction were considered for entry into the trial. The inclusion criteria were $(a)$ chest pain suggestive of myocardial infarction, $(b)$ admission to hospital at such a time that treatment could begin within six hours from the onset of symptoms, and $(c)$ the presence on the electrocardiogram of $1 \mathrm{~mm} \mathrm{ST}$ segment elevation in the standard leads or $2 \mathrm{~mm}$ in the precordial leads on admission and at least 30 minutes after the onset of symptoms.

Exclusion criteria were: (a) cerebrovascular disease; $(b)$ history of peptic ulceration or other disease with bleeding tendency; (c) blood pressure > $180 / 110 \mathrm{~mm} \mathrm{Hg}$ on admission; (d) surgical treatment within the previous four weeks; $(e)$ cardiopulmonary resuscitation or central vascular cannulation before treatment started; $(f)$ previous entry into the trial or previous treatment with streptokinase; $(g)$ valvar heart disease with atrial fibrillation; $(h)$ diabetes for which insulin treatment had been started before the patient was 30 ; $(i)$ anticoagulant treatment; $(j)$ current pregnancy; $(k)$ age $>70$ years. These exclusion criteria were chosen to avoid the predictable complications of streptokinase and they are standard for a trial of this nature. The reasons for the exclusion of patients were examined. Patients could have had more than one reason for exclusion. Thus the inclusion criteria were considered first, in the order stated, and we considered the exclusion criteria only in those patients in whom all the inclusion criteria were fulfilled. Exclusion criteria were also considered in the order stated. Once we knew of one reason for a patient to be excluded we did not seek further reasons.

\section{Results}

During the period October 1984 until June 1985403 patients (277 men and 126 women) presented to the participating centres with a clinical diagnosis of suspected acute myocardial infarction and were considered for entry into the trial (figure). The mean age of the patients was 66.2 years (men 63.7 and women $71 \cdot 2$, range 24-92).

Two hundred and sixty $(65 \%)$ patients did not meet the inclusion criteria: $19(5 \%)$ reported atypical symptoms despite a clinical diagnosis of suspected myocardial infarction, $157(39 \%)$ presented more than six hours after the onset of symptoms, and $84(21 \%)$ did not demonstrate the required electrocardiographic changes.

Forty five of the 143 patients who did fulfil the inclusion criteria had specific contraindications to thrombolysis as defined by the trial protocol (table

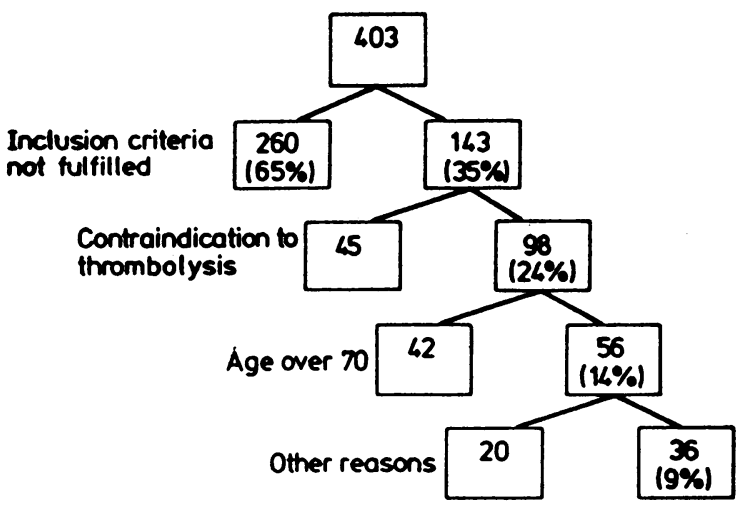

Figure Reasons for exclusion of patients from a trial of intravenous streptokinase in myocardial infarction.

1). The most important reasons for exclusion were history of peptic ulceration, systemic hypertension, and resuscitation.

Thus $98(24 \%)$ patients were suitable for thrombolysis. Of these, 42 were over the age of 70 years and were excluded on this criterion alone. Therefore, $56(14 \%)$ patients were eligible for recruitment. Finally $36(9 \%)$ were recruited. The reasons for the exclusion of the remaining 20 were inability to obtain consent in six patients, cardiac arrest before randomisation in two, and local administrative reasons in twelve.

\section{Discussion}

These data suggest that only a small proportion of patients with acute myocardial infarction are suitable for thrombolysis if the criteria used in this study are applied. This has two implications. First, any conclusions about efficacy of thrombolysis can only be applied to this group of patients. Secondly, if thrombolysis becomes clinically useful it may be inappropriate for over three quarters of all patients with myocardial infarction. This does not reduce the

Table 1 Patients excluded because of contraindications to thrombolysis

\begin{tabular}{lc}
\hline Contraindication & No. patients \\
\hline Cerebrovascular disease & 5 \\
Peptic ulcer/bleeding & 10 \\
Blood pressure > 180/110 mm Hg & 13 \\
Recent operation & 1 \\
Resuscitation & 12 \\
Previous streptokinase & 0 \\
Valve disease & 0 \\
Diabetes & 2 \\
Anticoagulants & 2 \\
Pregnancy & 0 \\
Total & 45 \\
\hline
\end{tabular}


value of thrombolysis in patients who are suitable and in whom it may prove to be very useful.

The problem of patient recruitment is common to many thrombolysis trials. Khaja et al recruited 54 $(18 \%)$ of a possible 305 patients into a trial of intracoronary streptokinase. ${ }^{12}$ There was no upper age limit in this protocol, although patients had to present within six hours of the onset of symptoms. The European cooperative trial of intravenous streptokinase, published in 1979, set a time limit of 12 hours from symptom onset and required a birthdate of 1900 or later for inclusion. ${ }^{8}$ These workers stratified $512(22 \%)$ of 2338 patients and finally randomised $315(13.5 \%)$. In the treatment group there were 31 patients (12 streptokinase, 19 placebo) in whom the 12 hour limit was exceeded. A recent study by Sainsous et al reported that of 1105 patients with myocardial infarction $175(15.8 \%)$ were suitable for intravenous thrombolysis. ${ }^{3}$

Low recruitment rates are a feature of other infarct intervention studies. Lie et al recruited $29 \%$ of all patients with infarcts into a trial of lignocaine, ${ }^{14}$ Yusuf et al randomised $10-20 \%$ of all possible patients into a trial of atenolol, ${ }^{15}$ and Muller et al recruited $8 \%$ into a study of nifedipine. ${ }^{16}$ Contraindications to treatment varied in the trial protocols but important factors for the low recruitment rates in all these trials were the age of the patients and the time taken for them to present.

Attempts to widen the application of thrombolysis could be aimed at the reasons for exclusion of patients as described above. If the treatment is to remain safe, however, the number of patients with contraindications to specific treatments with different thrombolytics is unlikely to be reduced. Recruitment would be improved if a thrombolytic agent with fewer side effects could be developed. There is a great deal of interest in new agents, particularly tissue plasminogen activator. Tissue plasminogen activator is claimed to have very little systemic effect. Early results, however, show an incidence of haemorrhage similar to that with high dose streptokinase. ${ }^{17}$ It would be difficult, therefore, to use tissue plasminogen activator in patients with almost any one of our exclusion criteria. Hypersensitivity will not be a problem because tissue plasminogen activator is not antigenic; but nor is streptokinase if patients are premedicated with hydrocortisone.

Reducing the time taken for patients to present would be important. Sainsous et al reported a mean in hospital delay of $10.3(10.5)$ hours; patients presenting more than $\mathbf{4 8}$ hours after infarction were excluded. ${ }^{13}$ This delay could be reduced by patient education and the use of mobile coronary ambulances. ${ }^{18}$ Public education in cardiopulmonary
Table 2 Patients excluded on the grounds of age alone (cumulative frequency)

\begin{tabular}{|c|c|}
\hline Upper age (yr) & Additional number of patients suitable \\
\hline $\begin{array}{r}71 \\
72 \\
73 \\
74 \\
75 \\
76 \\
77 \\
78 \\
79 \\
80 \\
90 \\
100\end{array}$ & $\begin{array}{r}1 \\
3 \\
8 \\
11 \\
18 \\
22 \\
25 \\
27 \\
29 \\
34 \\
40 \\
42\end{array}$ \\
\hline
\end{tabular}

resuscitation may also increase the number of so. called "sudden death survivors" who may prov suitable for thrombolysis. ${ }^{19}$

The question of age is complex. The upper age limit for this study was 70 years. Forty two patients 1 were excluded on the basis of age alone. If the uppero age limit were to be raised to 75 years a further 18 patients would be recruited (table 2). By raising it to 80 years a total of 34 extra patients would be eligible for the trial, thus increasing the proportion of suit $-\frac{\infty}{y}$ able patients to $22 \%$. This may be a useful way of improving recruitment if it is shown that long terme survival is improved by thrombolysis alone and that the incidence of complications is no higher in this older age group. If future studies indicate that sur $\frac{}{\mathrm{D}}$ vival after thrombolysis can only be improved by subsequent coronary angioplasty or bypass graftinge it might be inappropriate to consider this treatmen? in patients over the age of 70 because surgical inter vention is usually considered in these patients only: when angina is severe. A recent study from Ver $\overrightarrow{-D}$ heugt et al has indicated that haemorrhage is more frequent after intracoronary thrombolysis in? patients over the age of $60 . .^{20}$ If this trend applies over the age of 70 then this consequence would alsof have to be considered.

We believe, therefore, that although throm 웅 bolysis, with or without subsequent angioplasty o surgery, may lead to improved long term survivalo․․․ this treatment may be applicable to only a small pro+ portion of patients with myocardial infarction.

\section{References}

1 Reimer KA, Lowe JE, Rasmussen MM, Jennings RBC The wavefront phenomenon of ischaemic cell death 1. Myocardial infarct size vs duration of coronary ${ }^{+}$ occlusion in dogs. Circulation 1977;56:786-98.

2 Rentrop KP, Feit F, Blanke $\mathrm{H}$, et al. Effects of intra coronary streptokinase and intracoronary nitro glycerin infusion on coronary angiographic patternsD and mortality in patients with acute myocardiaf infarction. N Engl $\mathcal{f}$ Med 1984;311:1457-63. 
3 Alderman EL, Jutzy KR, Berte LE, et al. Randomized comparison of intravenous versus intracoronary streptokinase for myocardial infarction. Am $\mathcal{F}$ Cardiol 1984;54:14-9.

4 Kennedy JW, Gensini GG, Timmis GC, et al. Acute myocardial infarction treated with intracoronary streptokinase: a report of the Society for Cardiac Angiography. Am $\mathcal{F}$ Cardiol 1985;55:871-7.

5 Anderson JL, Marshall HW, Bray BE, et al. A randomized trial of intracoronary streptokinase in the treatment of acute myocardial infarction. $N$ Engl $\mathcal{F}$ Med 1983;308:1312-8.

6 Kennedy JW, Ritchie JL, Davis KB, Fritz JK. Western Washington Randomized Trial of Intracoronary Streptokinase in Acute Myocardial Infarction. $N$ Engl f Med 1983;309:1477-82.

7 Aber CP, Bass NM, Berry CL, et al. Streptokinase in acute myocardial infarction: a controlled multicentre study in the United Kingdom. $B r$ Med $\mathcal{F} 1976$; ii: $1100-4$.

8 European Study Group for Streptokinase in Acute Myocardial Infarction. Streptokinase in acute myocardial infarction. N Engl f Med 1979;301:797-802.

9 Schroder R. Systemic versus intracoronary streptokinase infusion in the treatment of acute myocardial infarction. $\mathcal{F} \mathrm{Am}$ Coll Cardiol 1983; 1(5):1254-61.

10 Anderson JL, Marshall HW, Askins JC, et al. A randomized trial of intravenous and intracoronary streptokinase in patients with acute myocardial infarction. Circulation 1984;70:606-18.

11 Simoons ML, Serruys PW, Brand M, et al. Improved survival after early thrombolysis in acute myocardial infarction. Lancet 1985;ii:578-82.

12 Khaja F, Walton JA, Brymer JF, et al. Intracoronary fibrinolytic therapy in acute myocardial infarction: report of a prospective randomized trial. $N$ Engl $\mathcal{f}$ Med 1983;308:1305-11.

13 Sainsous J, Serradimigni A, Richard JL, Guize L, LeConte T, Tanielian PH. How many patients with acute myocardial infarction could be treated in France by intravenous streptokinase? Results of a prospective trial [Abstract]. Eur Heart $\mathcal{F}$ 1985;6(suppl I):67.

14 Lie KI, Wellens HJ, van Capelle FJ, Durrer D. Lidocaine in the prevention of primary ventricular fibrillation. A double-blind, randomized study of 212 consecutive patients. $N$ Engl F Med 1974;291:1324-6.

15 Yusuf S, Sleight P, Rossi P, et al. Reduction in infarct size, arrhythmias and chest pain by early intravenous beta blockade in suspected acute myocardial infarction. Circulation 1983;67(suppl I):1.32-41.

16 Muller JE, Morrison J, Stone PH, et al. Nifedipine therapy for patients with threatened and acute myocardial infarction: a randomized, double-blind, placebo-controlled comparison. Circulation 1984; 69:740-7.

17 The TIMI Study Group. The thrombolysis in myocardial infarction (TIMI) trial. Phase I findings. $N$ Engl f Med 1985;312:932-6.

18 Mathewson ZM, McCloskey BG, Evans AE, Russell CJ, Wilson C. Mobile coronary care and community mortality from myocardial infarction. Lancet 1985; i:441-3.

19 Cobb LA, Baum RS, Alvarez H, Schaffer WA. Resuscitation from out-of-hospital ventricular fibrillation: 4 years follow-up. Circulation 1975;52(suppl III): 223-35.

20 Verheugt FWA, van Eenige MJ, Res JCJ, et al. Bleeding complications of intracoronary fibrinolytic therapy in acute myocardial infarction: assessment of risk in a randomized trial. Br Heart $\mathcal{F}$ 1985;54:455-9. 